\title{
Responses and Coping of Foreign Peace Keepers Working in Liberia to Threat of Ebola during the 2014 Outbreak
}

\author{
Kishore Kumar Das, Adeel Gardezi \\ Level 2 Hospital, UNMIL, Monrovia, Liberia \\ Email: kishorek50@hotmail.com
}

Received 12 June 2015; accepted 9 August 2015; published 12 August 2015

Copyright (C) 2015 by authors and Scientific Research Publishing Inc.

This work is licensed under the Creative Commons Attribution International License (CC BY).

http://creativecommons.org/licenses/by/4.0/

(c) (i) Open Access

\section{Abstract}

The Ebola virus poses two inter-linked threats-the disease itself and fear of the disease. In Liberia, where over 4500 people have died from Ebola, a UN peacekeeping mission is currently operational (UNMIL). The study was conducted among 240 UN peace keepers of 9 different countries working in Liberia. The study period was from July 2014 to December 2014. The level of anxiety of the subjects was assessed in Hospital Anxiety and Depression Scale (HADS). Reactions towards Ebola were mixed. There was a degree of fear but the level of anxiety was not so predominant. The reasons for panic were-no known cure, a perceived fear of discrimination and stigmatization, a fear that upon death one's body will not be taken back home, there may not be proper burial or even cremation, contrary to custom. Among the study population, $55 \%$ think of themselves as being at greater risk than their colleagues, $19 \%$ want to leave the $\mathrm{UN}$ mission area. The mean level of Anxiety was $10.87 \pm 6.93$ in HAD scale where as mean level of Depression was $3.98 \pm 4.14$. Psychological support is a key priority in the response to this relatively unknown and poorly understood yet lethal disease.

\section{Keywords}

Ebola, Psychological Response, Disease Outbreak

\section{Introduction}

Over the last four decades, several outbreaks of the Ebola virus have caused fear and economic turmoil in parts of Africa including the Democratic Republic of Congo, Uganda, Gabon and Sudan. The 2014 Ebola outbreak in West Africa has been the most severe case in history and precipitated a sea change in attitudes to the disease: 
now it is no longer seen solely as a malady confined to isolated regions of the Africa, but as a global health threat (Sarathi, Dhanashree, Sagar, Thomas, Stanislaw et al., 2014; Lei \& Hao, 2014). According to WHO facts sheets and Wikipedia Ebola viral disease (previously called Ebola hemorrhagic fever) presents with non-specific symptoms like high fever, weakness, nausea, headache, vomiting and diarrhea. Patients often exhibit the classical signs of visible and invisible bleeding: deep-set eyes, ghost-like expressionless face, extreme lethargy and shock. Those who die do so usually within a couple of weeks of the disease's onset, the gruesome mode of death and resulting stigmatization etched deeply into the public imagination. Different people show different psychological reactions to an outbreak of this kind (Red Cross, 2015) (Ebola and Psychological Support during an Outbreak of Ebola Virus Disease).

During any outbreak like SARS, Influenza or Ebola there are two threats to a community-the disease and fear of the disease. There is an elevated level of stress and depression. Protective measures like hygiene and personal protective equipment may prevent one from catching the disease, particularly for those who work in hospitals treating infected patients, but the fear of the disease is often higher than the actual disease risk (Rober, Jonathan, Leslie, Jocelyn, Nathalie et al., 2003) (Devanand, Wendy, Stephen, \& Lachlan, 2008). People living in poor and rural communities who have limited education and little knowledge often suffer the worst effects of fear and stigmatization. People sometimes cope with their fears by blaming others and relationships can break down under the strain, isolating individuals and communities. Contrary to widely publicized reports of panic, the affected people do not report excessive psychological symptoms (Jesus, Jaime, Maurillo, Cuauhtemoc, Anaid et al., 2010; Michael, Sara, \& Kasisomayajula, 2013).

Ebola viral fever has several characteristics that contribute to an excessive emotional reaction out of proportion to the actual threat. Though it has been well known to scientists since 1976, and is recognized as an important public health pathogen and bio threat pathogen of category A, it is a relatively new disease to the general public across the world (CDC, 2014). As such, suspicion about its origin and uncertainty about its mode of transmission, stigmatization of the diseased or affected communities.

All of the previous known Ebola outbreaks were self-limiting on many occasions. But the recent epidemic in West Africa spread relentlessly and showing a bushfire pattern of progress with constant changes in epicenter. Some countries with appropriate and prompt response could contain the disease shortly (Heinz \& Thomas, 2011).

In some countries in West Africa, there are UN military peace keeping missions comprising personnel from multiple contributing nations. During the outbreak, the objectives of the mission have been changed or modified, according to UNMIL website. Response of the peace keepers to Ebola outbreak has varied from individual to individual. This study documents and analyses some of the psychological and emotional responses of UN peacekeepers working in Liberia, which has recorded the highest number of cases and death in 2014 Ebola viral disease outbreak. The UN peace keeping operation in Liberia consists of over 4000 military personals from 39 countries (as per data on 31 December 2014) (UNMIL fact sheet, 2014).

\section{Methodology}

The study was conducted among the UN peace keepers working in Liberia. A total 240 peace keepers from 9 different countries were interviewed through a set questionnaire. The study period was from July 2014 to December 2014. Documentation reviewed included routine UN correspondence, delegation visits, policies for the contingent and individual's own reaction to regular events were also observed. The levels of anxiety of the subjects were assessed in Hospital Anxiety and Depression Scale (HADS). Each item on the questionnaire is scored from $0-3$ and this means that a person can score between 0 and 21 for either anxiety or depression, a cut-off point of $8 / 21$ for anxiety or depression. For anxiety (HADS-A) this gave a specificity of 0.78 and a sensitivity of 0.9. For depression (HADS-D) this gave a specificity of 0.79 and a sensitivity of 0.83 .

\section{Results and Observations}

Initially there was a state of denial about the spread of the disease. Those working in the capital Monrovia perceived the danger first. Alarm and panic gradually became more widespread as the number of cases increased, the media began to report on the issue, the WHO and CDC raised alert levels, international medical volunteers and UN staff were infected with Ebola. Initial denials turned into irrational acts. Local Liberian people working inside UN camps were sacked without cause, gates were closed to everyone other than members of one's own country contingent, social mixing between different nationalities stopped, people's attitudes became unwelcom- 
ing and suspicious towards strangers, and there was little interaction or collaboration with local people, politicians or organizations from July until November 2014.

The United Nation Mission in Liberia (UNMIL) did not have any dedicated Ebola treatment units for its own staff and the medical evacuation plan for Ebola cases was not clear or communicated. Thus there were confusion and rumors: e.g.no treatment for UN personnel, no blood test, body will be cremated etc. Medical facilities formulated their own safety protocol by refusing admission of febrile cases, and there was frequently a false alarm upon arrival of non-Ebola cases, which appeared irrational to the UN Mission Authority. Stating a dissatisfaction with the services provided the UN did not offer a risk premium to staff in its medical facilities, which was demoralizing for medical staff. On the contrary, substantial logistic problems like insufficient supply of Personal Protective Equipments was disinfectant etc, lack of coordination and absence of supervision was also observed. Experts found several limitations of treating Ebola cases within medical facilities.

Local and foreign staffs viewed each other suspiciously; suspecting anyone else could be a carrier of the virus. Strict preventive measures that may have seemed irrational or paranoid-like closing gates for all, restricting locals to enter UN compounds, stopping works and businesses with public — did reduce worries among the UN respondents. Even offering prayer with member of other nationals was politely discouraged, the authors observed.

Although the situation has not returned to as it was prior to the outbreak, the situation has improved gradually since December 2014. Factors in this positive trend include the decline in number of cases, people having a better understanding of the disease and how to protect against it, a sufficient number of Ebola beds established, quick testing made available, clarification of the medical evacuation available for international staffs, screening established at gates to UN compounds, compulsory hand washing, and the a modified way of socialization without shaking hands.

Reactions towards Ebola among UNMIL personnel were mixed. All considered working within an outbreak as an occupational hazard. Those who were afraid (19\% of the peace keepers) and did not wish to take the risk of staying in Liberia gave the opinion that they are trained for battle and the threat of death in warfare, but not Ebola. The majority (81\%) however were in favor of continuing the mission. Commitment to the profession, home country thus to UN and for some individuals financial benefits were motivations.

There was a degree of fear but the level of anxiety was not so predominant. The reasons for panic were that there was no known cure, no treatment facility, a perceived fear of discrimination and stigmatization, a fear that upon death one's body will not be taken back home, fear of one's family getting no compensation if death occurs due to Ebola, and that there may not be proper burial or even cremation, contrary to custom. There was fear of discrimination upon returning home. Those who were more panicked often transmitted it to others by continuously dramatizing the danger; family members back home were also panicked as a result and transmitted it back.

Among the study population 68\% think that Ebola is a global threat, 55\% think they are at greater risk than their colleagues because of the nature of their job, $70 \%$ believed that they have sufficient knowledge about the mode of transmission and personal protection of Ebola, and 59\% believe that the level of precautions taken by their respective unit to prevent infection was enough. $81 \%$ of peacekeepers wanted to complete their tenure in Liberia even if their own government desired to pull their contingent out. Regarding the risk of getting infection $54 \%$ thought that working in public places is more risky while $28 \%$ thinks hospital to be most risky place for viral transmission.

Mean level of Anxiety was $10.87 \pm 6.93$ in HADS scale where as Mean level of Depression was $3.98 \pm 4.14$ in HADS scale.

Members of UN medical facilities (level 2 hospitals) demonstrated more anxiety than others. One doctor had been repatriated on psychological grounds related to Ebola. One private reportedly fainted when an ambulance carrying a suspected Ebola case was passed to him. The death of a colleague in a non-Ebola febrile cause precipitated the panic attack, which manifested as transient unconsciousness. There was an increase in requests for a recommendation of repatriation on medical grounds for shoulder pain, back pain etc.

The majority (90\%) reported that a feeling of anxiety increased when alone. They spent time in games, gossip, movies or prayers. Average time spent in prayers also increased in comparison to time back home. The level of anxiety in an individual often fluctuated with the hike in number of Ebola cases.

There was a tendency to hide symptoms among UNMIL personnel. Afebrile patient hiding symptoms for more than 10 days resulted in death, one Ebola positive case did not report their fever during the initial days of 
becoming symptomatic, resulting in a number of colleagues he met during that period being placed in quarantine. Personnel were observed taking paracetamols and antibiotics to pass routine temperature checks. UN later issued a letter to all military contingents indicating it was prohibited for any personnel to keep drugs without prescription.

An increased number of soldiers reported to hospitals with non organic complaints including vague abdominal pain, nausea, weakness, body ache, and palpitation. Insomnia was the commonest complaint, experienced by $95 \%$ of the subjects. Symptom induced anxiety like palpitation, raised blood, fainting was also observed among them.

Peacekeepers quarantined for Ebola contact were subjected to the significant and sustained mental pressure of remaining in isolation for a period of 21 days. Nightmare was very frequent, passing the day was relatively easy compared with the night. Those placed in voluntary or mandatory quarantine had concerns over their personal safety, a fear of carrying the disease back home and transmitting the disease to family members, stigmatization and interpersonal isolation. Discrimination and the avoidance of friends and colleagues were also depressing factor for those in quarantine. Some with a better understanding of the facts of Ebola transmission went into self quarantine while others were forced to do so and experienced severe panic attack during the night and was about to break quarantine.

From command and control point of view Ebola was safeguard to keep discipline within the unit. The troops were afraid and paid more attention to medical advices and adapted personal hygiene like regular hand wash before and after any work. No known complaint of unauthorized sex or sexual abuse with locals by troops was reported, according to medical officers of the units.

\section{Discussion}

The Ebola virus has flared up several times since its discovery in 1976, each time killing with abandon before slinking back into the wilderness. This time in West Africa, Ebola has spread farther and faster than previous epidemics. It has exposed the woeful unpreparedness of health systems and the international health agencies to cope with a serious Ebola outbreak in multiple countries (Sarathi, Dhanashree, Sagar, Thomas, Stanislaw et al., 2014; Lei \& Hao, 2014; Heinz \& Thomas, 2011). As previous, the over-riding theme of the 2014 Ebola outbreak was fear.

Apart from the virus, surrounding local and international developments created fear among the foreign peacekeepers working in Liberia. The outbreak started in Guinea and gradually increased the geographical radius. The WHO declared a world health emergency and the forecast for the potential spread of the disease given by the WHO and CDC was frightening. In September the CDC predicted a worse case scenario of 1.4 million cases by January 2015. In October WHO predicted 10,000 cases per week by December, according to WHO and CDC website (WHO, 2014).

Symptom induced worry as seen in other epidemics was seen among the study population. Any illness, febrile or non-febrile, increased the level of anxiety [Wu, Fang, Liao, Ng, Wu, Leung, Fielding, \& Cowling, 2014]. During the peak in September, October and November 2014, Ebola was the only topic of discussion. Perhaps people have more concern about dealing of their dead bodies. Dead bodies of Ebola victims are known to be very infectious and considered untouchable. Dead body will not return home if one die of Ebola was not mentally acceptable to all.

From the graphics published in Economist newspaper it is clear that Ebola spreads very rapidly, but when the benefits of health protective behavior are understood and the psychological barriers to it are overcome the number quickly drops, as seen in Liberia during the study period (David \& Elizabeth, 2012). As the number of cases dropped anxiety also dropped with it. Reading and watching news on Ebola over and over increased anxiety; the author personally had anxiety while following Ebola outbreak on media (Economist, 2014) (Ebola in Graphics, 2015).

An important objective for any future outbreak control strategy must be to prevent excessive fear, which, it is expected, would reduce stigma and other negative outcomes. The value of openness in the provision of public information is important. There should have been a multi-sectoral and multidisciplinary taskforce committee on epidemics in every country for effective collbroation between local health authorities, governments, international agencies and NGOs (Anthony, Joseph, Miriam, Alex, Issa, \& Jane, 2014; Kinsman, 2012; Mona, Tamara, Tim, Barbara, Keith et al., 2014) (Devanand, Wendy, Stephen, \& Lachlan, 2008). 
Pre sensitization helps to reduce fear. In 2014 there were two Ebola outbreaks, one in West Africa and one in Democratic Republic of Congo. The Congo outbreak ended after just 66 cases and 49 deaths. Whereas, in Liberia there have been more than 4500 deaths.

It was the seventh outbreak in the former Zaire. Congolese people have been hearing about Ebola for many years (Anthony, Joseph, Miriam, Alex, Issa, \& Jane, 2014; Kinsman, 2012), whereas, for UN peace keepers in Liberia Ebola was a new disease on which they had not been vaccinated and had limited understanding. Psychologists who study risk perception and people's potential reactions to unpredictable threats say that people can prepare themselves psychologically if they know the facts beforehand and therefore feel more in control if such an event were to occur (Andrew, 2001; Erica, 2005; David \& Elizabeth, 2012; Demobly, 2011; James, Theodore, \& Julie, 1965). Foreign Peace keepers those had been counseled about Ebola before coming to the mission coped better with the situation, this study observed. Before the assignment of mission for military personnel it is natural to have some concern. These may include concerned family and friends, personal fear, lack of knowledge about the disease, transmission, treatment, not knowing what it will be like on the ground etc. In order to make it easier to prepare authorities should take such concerns seriously, gather and disseminate information and enable personnel to learn about the disease, get the right information from a reliable source, and ensure individuals comply with security and protective measures.

There is no alternative to preparedness. Hospital Preparedness is critical for the early detection and management of a public health emergency (Li, Huang, \& Zhang, 2008). Among the three worst hit countries Liberia, Guinea and Sierra, Liberia was declared Ebola free first as it could increase treatment facilities relatively faster. That encouraged people to get treatment and not to hide from doctors and aid workers.

Ebola qualifies as a bioweapon by definition and the reaction to it was similar on the ground (Andrew, 2001). Local Liberian Media published an idea that Ebola is an escaped military bioweapon and a few foreign peace keepers followed the reports. In another opinion it had been genetically modified and could have been an accident in the lab experimenting upon the Ebola vaccine. However, DNA analysis of samples from current outbreak found it to be perfectly natural (WHO Ebola Response Team, Agua, Ariyarajah, Aylward, Blake, Brennan, Cori et al., 2015) (Stephen, Augustine, Kristian, Rachel, Daniel et al., 2014). The panic attacks that a few individual peace keepers suffered cannot be taken as an indication that there was mass psychogenic illness (hysteria), but some symptoms presented by the respondents at hospitals shows that they were having palpitation, insomnia, weakness, malaise, abdominal pain and body aches without any organic etiology. These symptoms were seen in other Epidemic as well (Erica, 2005; Demobly, 2011; James, Theodore, \& Julie, 1965; Li, Huang, \& Zhang, 2008).

\section{Conclusion}

In the response to this relatively unknown and poorly understood yet lethal disease, psychological support is a key priority. It is vital not only in ensuring wellbeing but also to counteract the threat to health and safety that fear, stigmatization and misconception poses. Any future outbreak control strategy must include steps to prevent excessive fear. However, a degree of fear is healthy in ensuring people pay due attention to the threat of the disease.

Within an epidemic if one is not scared then he or she is not careful. People residing within the Epidemic zone have to embrace their fear to a degree but should not let it paralyze them. The authority's or government's response should be one of effective coordination, surveillance, and provision of information calling for special hygienic precautions when handling any disease. Providing assurances and accurate information to people fighting in the frontline of the epidemic is one of the most important components. Within the hospitals, responses should include recruiting a motivated team of healthcare professionals, an isolation unit away from other patients with a separate entry, implementing mental health support interventions from the start, addressing problems with logistics and communications and overcoming resistance to directives among people through clear and effective communication.

\section{References}

(2015). Ebola and Psychological Support during an Outbreak of Ebola Virus Disease. http://pscentre.org/ebola/

(2015). Ebola in Graphics. http://www.economist.com/blogs/graphicdetail/2015/01/ebola-graphics

Andrew, M. (2001). Mass Hysteria Is Seen as Main Threat from Bioweapons. BMJ, 323, 1023. 
http://dx.doi.org/10.1136/bmj.323.7320.1023a

Anthony, K. M., Joseph, F. W., Miriam, N., Alex, O., Issa, M., \& Jane, R. A. (2014). Ebola Viral Hemorrhagic Disease Outbreak in West Africa-Lesson from Uganda. African Health Science, 14, 495-501. http://dx.doi.org/10.4314/ahs.v14i3.1

CDC (2014). About Ebola Viral Disease Update: Ebola Virus Disease Epidemic-West Africa. http://www.cdc.gov/vhf/ebola/about.html

David, P. D., \& Elizabeth, A. C. (2012). Incorporation of Individual Health Protective Decision into Disease Transmission Model: A Mathematical Framework. Journal of the Royal Society Interface, 9, 562-570. http://dx.doi.org/10.1098/rsif.2011.0325

Demobly, K. (2011). View Point: Episodes of Mass Hysteria in Africal School: A Study of Literature. Malawi Medical Journal, 23, 74-77.

Devanand, A., Wendy, M., Stephen, O., \& Lachlan, F. (2008). Influenza Pandemic_-Physicians and Their Obligations. Critical Care, 12, 217. http://dx.doi.org/10.1186/cc6918

Erica, W. (2005). Mass Psychogenic Illness. JAMC, 4, 172.

Heinz, F., \& Thomas, W. G. (2011). Ebola Haemorrhagic Fever. Lancet, 377, 849-862. http://dx.doi.org/10.1016/S0140-6736(10)60667-8

James, A. K., Theodore, I. F., \& Julie, S. (1965). Epidemic Hysteria: A Field Study. American Journal of Public Health, 55, 858-865.

Jesus, E. R., Jaime, E. V., Maurlio, M. G., Cuauhtemoc, M. J., Anaid, E. C., Melanie, T., \& Kingsley, A. (2010). Psychological Response of Family Members of Patients Hospitalized for Influenza A/H1N1 in Oaxaca, Mexico. BMC Psychiatry, 10, 104. http://dx.doi.org/10.1186/1471-244X-10-104

Kinsman, J. (2012). “A Time of Fear”: Local, National, and International Responses to a Large Ebola Outbreak in Uganda. Global Health, 8, 15. http://dx.doi.org/10.1186/1744-8603-8-15

Lei, Z., \& Hao, W. (2014). Forty Years of War Against Ebola. Journal of Zhejiang University Science B-Biomedicine \& Biotechnology, 15, 761-765.

Li, X. M., Huang, J. S., \& Zhang, H. (2008). An Analysis of Hospital Preparedness Capacity for Public Health Emergency in Four Regions of China: Beijing, Shandong, Guangxi and Hainan. BMC Public Health, 8, 319. http://dx.doi.org/10.1186/1471-2458-8-319

Michael, M., Sara, M., \& Kasisomayajula, V. (2013). The H1N1 Pandemic: Media Frames, Stigmatization and Coping. BMC Public Health, 13, 1116. http://dx.doi.org/10.1186/1471-2458-13-1116

Mona, R. L., Tamara, W., Tim, R., Barbara, M., Keith, R., Sue, K. et al. (2014). Hospital Preparedness and SARS. Emerging Infectious Diseases, 10. www.cdc.gov/eid

Rober, M., Jonathan, H., Leslie, V., Jocelyn, B., Nathalie, P., Molyn, L. et al. (2003). The Immediate Psychological and Occupational Impact of the 2003 SARS Outbreak in a Teaching Hospital. Canadian Medical Association Journal, 168, 12451251.

Sarathi, K., Dhanashree, K., Sagar, C. G., Thomas, J. P., Stanislaw, P. S., Bonnie, A., \& Jeffrey, A. J. (2014). The Emergence of Ebola as a Global Health Security Threat: From "Lessons Learned” to Coordinated Multilateral Containment Efforts. Journal of Global Infectious Diseases, 6, 164-177. http://dx.doi.org/10.4103/0974-777X.145247

Stephen, K. G., Augustine, G., Kristian, G. A., Rachel, S. G. S., Daniel, J. P., Lansana, K. et al. (2014). Genomic Surveillance Elucidates Ebola Virus Origin and Transmission during the 2014 Outbreak. Science, 345, 1369-1372. http://dx.doi.org/10.1126/science.1259657

UNMIL (2014). UNMIL Facts Sheet. http://www.un.org/en/peacekeeping/missions/unmil/facts.shtml

WHO (2014). Ebola Situation Report. http://www.who.int/csr/disease/ebola/situation-reports/en/

WHO (2014). Ebola Virus Disease. http://www.who.int/mediacentre/factsheets/fs103/en/

WHO Ebola Response Team, Agua-Agum, J., Ariyarajah, A., Aylward, B., Blake, I. M., Brennan, R., Cori, A. et al. (2015). West African Ebola Epidemic after One Year-Slowing but Not Yet under Control. New England Journal of Medicine, 372, 584-587. http://dx.doi.org/10.1056/NEJMc1414992

Wu, P., Fang, V. J., Liao, Q. Y., Ng, D. M. W., Wu, J. T., Leung, G. M., Fielding, R., \& Cowling, B. J. (2014). Response to Threat of influenza A (H7N9) and Support Poultry Markets, Hong Kong, 2013. Emerging Infectious Disease, 20.

http://www.cdc.gov/eid 